\title{
OPEN Utilization of the zebrafish model to unravel the harmful effects of biomass burning during Amazonian wildfires
}

\begin{abstract}
Sanja Babic ${ }^{1,2}$, Lara Čižmek ${ }^{1,2}$, Aleksandra Maršavelski ${ }^{3}$, Olga Malev ${ }^{4,5 \bowtie}$, Maryline Pflieger ${ }^{6}$, Ivančica Strunjak-Perović ${ }^{1,2}$, Natalija Topić Popović ${ }^{1,2}{ }^{2}$, Rozelindra Čož-Rakovac ${ }^{1,2} \&$ Polonca Trebše ${ }^{6 \bowtie}$

Amazonian wildfires in 2019 have raised awareness about rainforest burning due to increased emissions of particulate matter and carbon. In the context of these emissions, by-products of lignin thermal degradation (i.e. methoxyphenols) are often neglected. Methoxyphenols entering the atmosphere may form intermediates with currently unknown reaction mechanisms and toxicity. This study for the first time provides a comprehensive insight into the impact of lignin degradation products [guaiacol, catechol], and their nitrated intermediates [4-nitrocatechol, 4,6-dinitroguaiacol, 5-nitroguaiacol] on zebrafish Danio rerio. Results revealed 4-nitrocatechol and catechol as the most toxic, followed by 4,6DNG > 5NG > GUA. The whole-organism bioassay integrated with molecular modeling emphasized the potential of methoxyphenols to inhibit tyrosinase, lipoxygenase, and carbonic anhydrase, consequently altering embryonic development (i.e. affected sensorial, skeletal, and physiological parameters, pigmentation formation failure, and non-hatching of larvae). The whole-organism bioassay integrated with in silico approach confirmed the harmful effects of lignin degradation products and their intermediates on aquatic organisms, emphasizing the need for their evaluation within ecotoxicity studies focused on aquatic compartments.
\end{abstract}

The importance of the Amazonian basin as one of the largest ecosystems on Earth is extensive, from being the richest region hosting $25 \%$ of global biodiversity to being a huge carbon sink that eliminates up to $20 \%$ of excess atmospheric carbon and contributes to the biogeochemical functioning of the Earth system ${ }^{1-3}$. The Amazon is exposed to different altering factors such as wind blow-downs ${ }^{4}$, droughts ${ }^{5}$, but also deforestation and intensive fires ${ }^{6}$. Only in 2019, Brazil National Institute for Space Research ${ }^{7}$ has recorded 172,214 active fires across Brazil, among which 12,677 took place in the world's largest rainforest located in the Amazonian basin, popularly known as "Earth's lungs" (Table 1). Although these devastating Amazonian fires ceased, forest burning remains a regular occurrence in the Amazon basin (see current data for the year 2020, Table 1) with an average of 12,817 fires annually.

The primary concern of long-term vegetation biomass burning and atmosphere perturbation is the concurrent impact on climate and ecosystem function, as well as long-term inhalation of released gases and pollutants which can seriously impact human health, manifesting through respiratory problems, pulmonary disease, nerve disorders, atherosclerosis, or even cancer and death ${ }^{9,10}$. This is also evidenced by the fact that an increase of 59.5\% in the number of deaths observed in hospitalized children was reported in Roraima, one of the most fire-affected Amazonian regions in $2019^{11}$. Particulate matter and carbon are mainly pointed out as sole emissions from these fires ${ }^{12}$, while thermal degradation of lignin by-products (that comprises $18-35 \%$ of wood biomass) are often neglected ${ }^{13}$. Pyrolysis of lignin results in the formation of low molecular weight compounds

\footnotetext{
${ }^{1}$ Laboratory for Aquaculture Biotechnology, Division of Materials Chemistry, Ruđer Bošković Institute, Bijenička 54, Zagreb, Croatia. ${ }^{2}$ Center of Excellence for Marine Bioprospecting (BioProCro), Ruđer Bošković Institute, Bijenička 54, Zagreb, Croatia. ${ }^{3}$ Faculty of Science, Department of Chemistry, University of Zagreb, Horvatovac 102a, Zagreb, Croatia. ${ }^{4}$ Faculty of Science, Department of Biology, University of Zagreb, Roosevelt square 6, Zagreb, Croatia. ${ }^{5}$ Laboratory for Biological Diversity, Division for Marine and Environmental Research, Ruđer Bošković Institute, Bijenička 54, Zagreb, Croatia. ${ }^{6}$ Faculty of Health Sciences, University of Ljubljana, Zdravstvena pot 5, Ljubljana, Slovenia. ${ }^{\square}$ email: olga.malev@irb.hr; polonca.trebse@zf.uni-lj.si
} 


\begin{tabular}{|c|c|c|c|c|c|c|c|c|c|c|c|c|c|}
\hline \multirow[b]{2}{*}{ Year } & \multicolumn{12}{|c|}{ Month } & \multirow[b]{2}{*}{ Total } \\
\hline & 1 & 2 & 3 & 4 & 5 & 6 & 7 & 8 & 9 & 10 & 11 & 12 & \\
\hline 2015 & 38 & 71 & 25 & 20 & 11 & 34 & 365 & 4235 & 5004 & 2233 & 909 & 474 & 13,419 \\
\hline 2016 & 654 & 252 & 105 & 13 & 26 & 84 & 1087 & 3652 & 2785 & 1913 & 497 & 105 & 11,173 \\
\hline 2017 & 62 & 21 & 24 & 15 & 33 & 95 & 1534 & 4793 & 3185 & 1190 & 486 & 247 & 11,685 \\
\hline 2018 & 46 & 93 & 54 & 14 & 19 & 123 & 1346 & 2589 & 4928 & 1725 & 472 & 37 & 11,446 \\
\hline 2019 & 35 & 90 & 114 & 10 & 21 & 57 & 1371 & 6669 & 3026 & 548 & 573 & 163 & 12,677 \\
\hline 2020 & 197 & 73 & 77 & 12 & 15 & 122 & 2119 & 8030 & 4270 & 1265 & $323^{a}$ & $\mathrm{~b}$ & $16,503^{\mathrm{a}}$ \\
\hline
\end{tabular}

Table 1. The number of total active fires in the Amazonian basin detected by satellite during the last five years $^{8}$. Fire occasions that exceeded 1000 are marked in italics. ${ }^{a}$ The latest available data at the time of publication. ${ }^{\mathrm{b}}$ Data not available at the time of publication.

of phenolic structures-methoxyphenols (MPs), which are mainly represented by guaiacol (2-methoxyphenol), catechol (1,2-dihydroxybenzene), and syringol (2,6-dimethoxyphenol) ${ }^{14,15}$. Once MPs reach the atmosphere, they are prone to react with oxidants such as $\mathrm{OH}$ and $\mathrm{NO}_{3}$ radicals, $\mathrm{Cl}$ atom, and ozone molecules ${ }^{16}$. Complex migration and transformation processes of MPs in the troposphere can result in the formation of new airborne pollutants and increase the secondary organic aerosols (SOAs) yield. Although most of the published studies are computational predictions of MPs reactions and their rate constants, these studies are a good indicator of potential degradation products occurring mostly in the gaseous phase yielding from reactions with ozone (primary ozonides- $\mathrm{POZ}^{17}$ ) and $\mathrm{NO}_{3}$ (nitro-aromatics derivatives ${ }^{18}$ ). They can also partition into the aqueous phase and react with $\mathrm{OH}$ radicals (phenoxy- and catechol-species) ${ }^{19}$. MPs formed during lignin pyrolysis are found in the atmosphere, ambient particulate matter, drinking and surface water of riverine systems ${ }^{14,20}$. For example, concentration levels of guaiacol in Poland reached up to $0.63 \mu \mathrm{g} / \mathrm{L}$ in a river and $1.37 \mu \mathrm{g} / \mathrm{L}$ in drinking water ${ }^{14}$. Michałowicz ${ }^{21}$ also reported the occurrence of a high concentration of guaiacol exceeding $23 \mu \mathrm{g} / \mathrm{L}$ in Poland's surface waters. However, information about the occurrence and biological effects of nitrated MPs in aquatic ecosystems are still scarce.

Nitro-aromatic derivates are mostly less volatile and more water-soluble ${ }^{18}$ thus in great proportion remain in the atmospheric aqueous phase. Accordingly, the enrichment of MPs in fog water is usually 3 to 4 times higher than the calculated values, potentially supported by dissolved fog-borne chemicals involved in the solubilization of these compounds ${ }^{22}$. Vast moisture formations in the Amazonian forest (e.g. flying rivers ${ }^{7}$ ) rise via convection and collide with the stratosphere enabling a majority of chemical compounds, including nitrated GUA and CAT intermediates, to easily cross the moisture column and reach the Earth's surface ${ }^{23}$. Thus, guaiacol, syringol, and their nitrated or chlorinated MPs can accumulate in different environmental compartments and food chains exerting potential toxic effects on non-target organisms including humans.

Despite a well-known fact that nitro groups in the molecular structure increase toxicity of aromatic phenols, to date there are no comprehensive data on the amount of guaiacol and catechol nitrated forms that could affect vertebrates, and ultimately humans. To our knowledge, Pflieger and Kroflič ${ }^{24}$ are the first that provided toxicological data for guaiacol and its nitro derivatives using marine bioluminescent bacterium Vibrio fischeri as a model test organism. Although this study revealed the harmful potential of nitrated guaiacol and pointed out the need for further toxicological testing, currently there are no other studies that address this class of chemicals in detail.

To fill this knowledge gap, our study focused on zebrafish Danio rerio as an in vivo vertebrate model platform which enabled high-throughput screening and (eco)toxicity evaluation of two common MPs formed during lignin pyrolysis-guaiacol (GUA) and catechol (CAT), and their nitrated forms: 4,6-dinitroguaiacol (4,6DNG), 5-nitroguaiacol (5NG) and 4-nitrocatechol (4NC). The whole-organism bioassay was integrated with in silico methods based on: (i) quantitative structure-activity relationship (QSAR) computation model for comparison of predicted lethal concentrations to fish with determined toxicity values, and (ii) molecular modeling focused on interactions of tested compounds with zebrafish main protein targets. MPs and nitro-MPs toxicity can arise from a variety of reasons: specific highly-reactive functional groups, the compounds's physicochemical properties, and the ability of the compound to bind to specific protein targets. As toxic potential of MPs can be caused by various parameters, a comprehensive approach utilizing three complementary types of data (i.e. in silico and in vivo data) applied in our study may improve the prediction and attempt to clarify MPs (or nitro-MPs) toxicity at organism level.

\section{Materials and methods}

Chemicals. Guaiacol (HPLC/GC grade; CAS No. 90-05-1; GUA), 5-nitroguaiacol (98\%; CAS No. 63693-1; 5NG), catechol ( $\geq 95.0 \%$; CAS No. 120-80-9; CAT), 4-nitrocatechol (97\%; CAS No. 3316-09-4; 4NC), ethyl 3-aminobenzoate methanesulfonate salt (HPLC/GC grade; CAS No. 886-86-2; MS-222) were purchased from Sigma-Aldrich (Deisenhofen, Germany). 4,6-dinitroguaiacol (95\%; CAS No. 19978-25-7; 4,6DNG) was obtained from Debye Scientific Co, Ltd. (Hong Kong, China). Artificial water ${ }^{25}$ was prepared using chemicals all purchased from Sigma Aldrich (Deisenhofen, Germany): calcium chloride dihydrate ( $\geq 99 \%$; CAS No. 1003504-8; $\left.\mathrm{CaCl}_{2} \times 2 \mathrm{H}_{2} \mathrm{O}\right)$, magnesium sulfate heptahydrate ( $\geq 98 \%$; CAS No. 10034-99-8; $\left.\mathrm{MgSO}_{4} \times 7 \mathrm{H}_{2} \mathrm{O}\right)$, sodium bicarbonate ( $\geq 99.7 \%$; CAS No. 144-55-8; $\mathrm{NaHCO}_{3}$ ), potassium chloride ( $\geq 99 \%$; CAS No. 7447-40-7; $\mathrm{KCl}$ ). 
Ethics statement. Animal housing and spawning were performed in aquaria units approved by the Croatian Ministry of Agriculture and according to the Directive ${ }^{26}$. All experiments in this study were conducted on the non-protected embryonic stages (up to $96 \mathrm{hpf}$ ), which do not require permission by animal welfare commissions ${ }^{26}$.

Zebrafish maintenance and embryo production. Zebrafish D. rerio [wildtype WIK strain obtained from the European Zebrafish Resource Center of the Karlsruhe Institute of Technology (KIT), Germany] were maintained in ZebTEC rack with Active Blue technology (Tecniplast S.p.A., Buguggiate, Italy) under a continuous photoperiod cycle of 14:10 h (light: dark). The water parameters were strictly controlled: temperature of $27.00 \pm 0.09^{\circ} \mathrm{C}$, conductivity at $494.80 \pm 2.61 \mu \mathrm{S} / \mathrm{cm}, \mathrm{pH}$ at $7.60 \pm 0.08$, dissolved oxygen $\geq 95 \%$ saturation. Adults were fed three times per day with frozen Artemia sp. (PETRA-AQUA tropical fish wholesale, Czech Republic).

A day before the experiment, males and females were transferred into the iSpawn-S Benchtop Size Breeding System (Tecniplast S.p.A.) at a 2:1 male to female ratio and kept separated by a divider. The next day, the divider was removed, and the spawning platform was lifted to initiate the spawning. After spawning eggs were collected within 15 min using an $800 \mu \mathrm{m}$ mesh and were rinsed to remove the debris.

Zebrafish embryotoxicity test (ZET). The test was performed according to the OECD Test Guideline ${ }^{27}$, with slight modifications. During dose range-finding experiments, embryos ( $n=10$ per concentration) were exposed to a wide range of concentrations spanning from $1.17 \mathrm{up}$ to $300.00 \mathrm{mg} / \mathrm{L}$ which were prepared in serial dilutions to obtain a testing range of interest, after which the main experiment was conducted.

Then, the main experiment was conducted in order to determine $\mathrm{EC}_{50}$ (half maximal effective concentration) and $\mathrm{LC}_{50}$ (half maximal lethal concentration) values. Fertilized eggs from 4- to 64-blastomeres were selected under a stereomicroscope (PRO-LUX, Croatia) and transferred individually into 24-well plates (NEST Scientific, USA) containing a final volume of tested sample $\left(2 \mathrm{~mL}\right.$ per well). Plates were incubated at $27.00 \pm 0.5^{\circ} \mathrm{C}$ in the Innova 42 incubator shaker (New Brunswick, Canada). Due to the photosensitivity of tested compounds, during the whole experiment specimens were kept in the dark. Daily, $30 \%$ of the test sample was replaced with a previously pre-warmed, aerated, and freshly prepared test solution ${ }^{27}$. For incubation and dilution of test solutions, artificial water ${ }^{25}\left(294.0 \mathrm{mg} / \mathrm{L} \mathrm{CaCl}_{2} \times 2 \mathrm{H}_{2} \mathrm{O} ; 123.3 \mathrm{mg} / \mathrm{L} \mathrm{MgSO}_{4} \times 7 \mathrm{H}_{2} \mathrm{O} ; 63.0 \mathrm{mg} / \mathrm{L} \mathrm{NaHCO} 3 ; 5.5 \mathrm{mg} / \mathrm{L} \mathrm{KCl}\right)$ was used. Negative controls within the experiment consisted of both internal ( $\mathrm{n}=4$ embryos for plate control) and external $(\mathrm{n}=24$ embryos on additional plate) controls. In all test solutions, $\mathrm{pH}$ was adjusted to 7.40 \pm 0.21 . The test was conducted with 10 embryos in three independent replicates, amounting to a total of 30 embryos per concentration. Every day lethal and sub-lethal effects were recorded using an inverted microscope (Olympus CKX41), equipped with Leica EC3 digital camera and LAS EZ 3.2.0 digitizing software (https://www.leica-micro systems.com/products/microscope-software/p/leica-las-ez/). At 96-h post-fertilization (hpf) percent of hatched larvae was also observed.

Morphometric analysis. After $96 \mathrm{~h}$ of exposure, 15 zebrafish larvae were randomly selected from each group and anesthetized with $100 \mathrm{mg} / \mathrm{L}$ of MS-222. Morphometric analysis was conducted on zebrafish larvae exposed to the corresponding $\mathrm{LC}_{50}$ value of each compound: $10.95 \mathrm{mg} / \mathrm{L}$ of CAT, $8.16 \mathrm{mg} / \mathrm{L}$ of $4 \mathrm{NC}, 211.40 \mathrm{mg} / \mathrm{L}$ of GUA, $76.02 \mathrm{mg} / \mathrm{L}$ of $5 \mathrm{NG}$, and $25.82 \mathrm{mg} / \mathrm{L}$ of 4,6DNG. Such high concentrations ( $\mathrm{LC}_{50}$ values) were chosen to determine which parameter, whether sensorial (eye area), physiological (yolk and pericardial sac area), or skeletal (head height) was the most affected under increased chemical load. The analysis was conducted using the Olympus BX51 light binocular microscope, while the measurements were performed using Microsoft AnalySIS Soft Imaging System software for DP70 Camera (https://www.olympus-lifescience.com/en/support/downl oads/).

Computational methods. The model of zebrafish carbonic anhydrase (CA; UniProt entry: Q92051) was modeled by I-TASSER server ${ }^{28}$. Only one model of zebrafish CA was obtained with C-score of 1.7 out of 2.0, which accounts for a highly reliable model. Structure templates identified in the Protein Data Bank (PDB) library are $3 \mathrm{mdz}, 1 \mathrm{fql}, 3 \mathrm{kwa}, 1 \mathrm{czm}, 3 \mathrm{uyq}$, and $1 \mathrm{flj}$. These PDB entries correspond to different human ( $3 \mathrm{mdz}$, $1 \mathrm{fql}, 3 \mathrm{kwa}, 1 \mathrm{czm}, 3 \mathrm{uyq})$ and rat (1flj) CA isozymes. The model structure of zebrafish CA obtained by I-TASSER server is deposited in ModelArchive (Project ID: ma-j4w5e). The homology model is validated by SAVES v5.0 server which showed good statistics for stereochemical, non-bonded interactions, and geometric parameters. Coordinates of $\mathrm{Zn}$ cation and water molecule coordinated to $\mathrm{Zn}$ cation were taken from the structure of carbon anhydrase deposited under PDB ID 1fql. Structures of ligands (chemical structures of tested compounds) were taken from ZINC database ${ }^{29}$ : guaiacol, GUA (ZINC13512224); 5-nitroguaiacol, 5NG (ZINC00295034), 4,6-dinitroguaiacol, 4,6DNG (ZINC4343573), catechol, CAT (ZINC13512214) and 4-nitrocatechol, 4NC (ZINC34800312). In this study, we used SwissDock server and AutoDock Vina 1.1.2 to dock the above-mentioned ligands to modeled $\mathrm{CA}^{30}$. The default parameters were used and the box centre in the receptor coordinate system was calculated by Ghecom $1.0^{31}$ and set to 66.18153 .29669 .746 whereas box dimensions were set to 20,20, $20 \AA$. This corresponds to the active site that contains $\mathrm{Zn}$ cation coordinated to three histidine moieties. Obtained docking results were analyzed in Chimera ${ }^{32}$.

Statistical analysis. Statistical analysis and graphical representation were performed using GraphPad Prism software version 6.0 (https://graphpad-prism.software.informer.com/6.0/). Prior to $\mathrm{LC}_{50} / \mathrm{EC}_{50}$ determination, data were subjected to logarithmic transformation (Fig. 1).

One-way analysis of variance (ANOVA) and Tukey's post hoc test were performed to examine the significance between negative control and tested samples, as well as among treatments. When the assumption for 

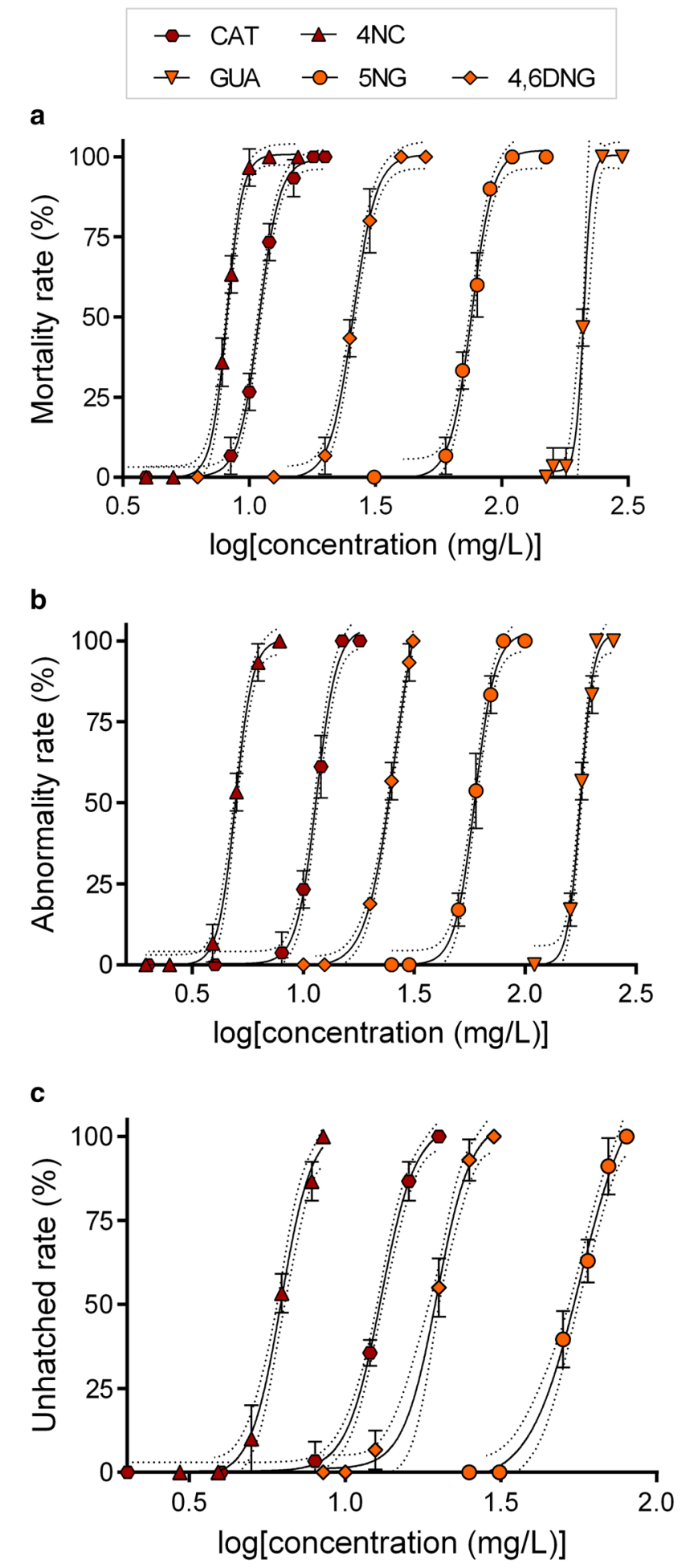

Figure 1. Concentration-response curves used for the calculations of the D. rerio: (a) mortality, (b) abnormality, and (c) unhatching rate after $96 \mathrm{~h}$ of exposure to CAT, GUA, 4NC, 5NG, and 4,6DNG. Error bars indicate standard deviations (SD). Dotted lines represent 95\% confidence intervals. Dose-response curves were generated using GraphPad Prism software version 6.0 (https://graphpad-prism.software.informer.com/6.0/).

normality was violated the Kruskal-Wallis One-way analysis of variance on ranks was performed. The results were expressed as means $\pm \mathrm{SD}$, and $\mathrm{p} \leq 0.05$ was used as a cut-off value of statistical significance throughout the paper. 


\begin{tabular}{|l|l|l|l|}
\hline \multirow{4}{*}{ (a) } & \multirow{4}{*}{ Tested compounds } & Experimental data & Ecotoxicological predictions \\
\cline { 2 - 4 } & Catechol (CAT) & $10.95 \pm 0.21$ & 22.23 \\
\hline \multirow{5}{*}{ Mortality } & 4-Nitrocatechol (4NC) & $8.16 \pm 0.10$ & 18.21 \\
\hline & Guaiacol (GUA) & $211.40 \pm 2.2$ & 68.73 \\
\hline & 5-Nitroguaiacol (5NG) & $75.96 \pm 1.92$ & 46.87 \\
\hline & 4,6-Dinitroguaiacol (4,6DNG) & $25.82 \pm 0.64$ & 20.39 \\
\hline (b) & Tested compounds & EC $_{50} \mathbf{9 6 - h}(\mathbf{m g} / \mathbf{L})$ \\
\hline \multirow{5}{*}{ Developmental abnormalit } \\
\hline \multirow{5}{*}{ Unhatching }
\end{tabular}

Table 2. Acute toxicity of guaiacol, catechol, and its nitrated products (mg/L): tabular view of toxicological predictions obtained from ECOSAR software for 96-h exposed fish and obtained experimental values for 96-h exposed zebrafish D. rerio embryos. Predicted values were obtained from ECOSAR v2.0 software (https://www. epa.gov/tsca-screening-tools/ecological-structure-activity-relationships-ecosar-predictive-model). ${ }^{\star}$ Maximal effect not reached.

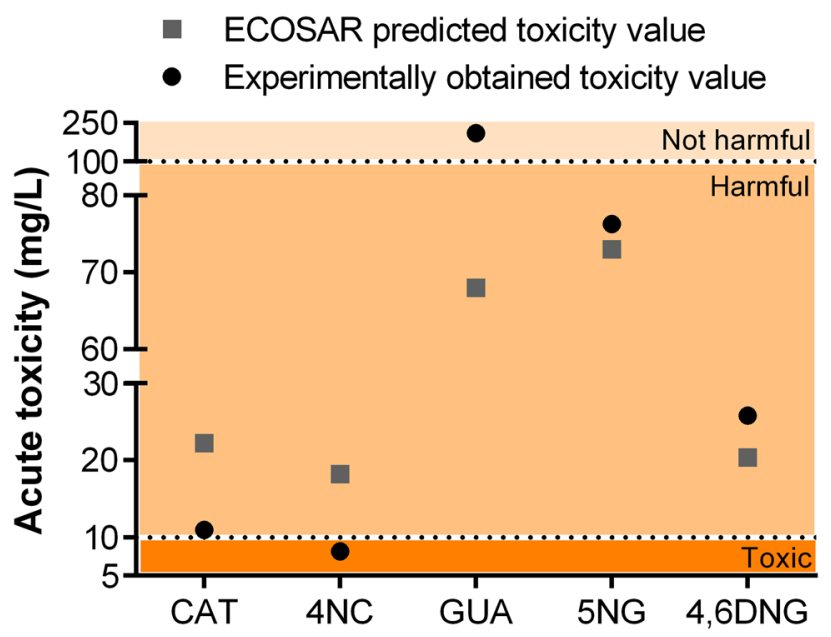

Figure 2. Graphical view of ECOSAR predicted and experimentally obtained toxicity values within the toxicity gradient according to the criteria set by the European Union ${ }^{34}$ (Very toxic $<1 \mathrm{mg} / \mathrm{L}$, Toxic $1<\mathrm{LC}_{50}<10 \mathrm{mg} / \mathrm{L}$, Harmful $10<\mathrm{LC}_{50}<100 \mathrm{mg} / \mathrm{L}$, Not harmful $\left.\mathrm{LC}_{50}>100 \mathrm{mg} / \mathrm{L}\right)$. Predicted values were obtained from ECOSAR v2.0 software (https://www.epa.gov/tsca-screening-tools/ecological-structure-activity-relationships-ecosar-predi ctive-model), while GraphPad Prism software version 6.0 (https://graphpad-prism.software.informer.com/6.0/) was used for data presentation.

Dark-red colour represents values and endpoints observed for CAT and 4NC, while orange colour represents GUA and its nitrated intermediates (5NG, 4,6DNG) in Figs. 1 and 4, as well as in Table S1.

\section{Results and discussion}

In vivo study: embryotoxicity test. Zebrafish embryos exposed to tested compounds developed lethal and sub-lethal alterations including different abnormalities and unhatching events. $\mathrm{LC}_{50}$ (for mortality rate) and $\mathrm{EC}_{50}$ (for abnormality and unhatching rate) values were extrapolated from concentration-response curves shown in Fig. 1. The rate of dead, abnormal, and/or unhatched specimens was concentration-dependent for all tested compounds (Fig. 1a-c). The lethality of the negative control group was less than 5\%. Compounds 4NC and CAT showed the highest toxicity with $\mathrm{LC}_{50}$ values of 8.16 and $10.95 \mathrm{mg} / \mathrm{L}$, respectively, followed by $4,6 \mathrm{DNG}>5 \mathrm{NG}>\mathrm{GUA}$. Experimental $\mathrm{LC}_{50} / \mathrm{EC}_{50}$ values and the predicted ones obtained by ECOlogical Struc- 
Figure 3. Recorded sublethal morphological effects in D. rerio embryos/larvae after 48, 72, and $96 \mathrm{~h}$ of exposure to CAT, 4NC, GUA, 5NG, and 4,6DNG. Negative control: normally developed embryo at (a) 48, (b) 72, and (c) 96 hpf. During exposure period alterations were manifested as: (d) yolk sac edema (arrow); (e) pericardial edema (asterisk), undeveloped tail region (arrow); (f) hatched fish with malformed spine (arrow); (g) underdeveloped tail and necrosis of its apical part (dashed arrow), rare pigments; (h) pericardial edema (asterisk), scoliosis (arrow), necrosis of the apical part of the tail (dashed arrow), rare pigments, not hatched; (i) scoliosis (arrows), blood accumulation in the brain region (dashed arrow); (j) pericardial edema (asterisk), yolk sac edema (arrow), scoliosis (dashed arrow); (k, l) pericardial edema (asterisk); (m) underdeveloped embryo: underdeveloped head (arrow), tail not detached (asterisk), delay or anomaly in the absorption of the yolk sac; (n) pericardial edema (asterisk), blood accumulation (arrow), not hatched; (o) pericardial edema (asterisk), blood clotting (arrow), not hatched; (p) blood accumulation at the yolk sac (arrow); (r) hatched fish with malformed spine; (s) pericardial edema (black asterisk), blood accumulation above the yolk sac (arrow), swelling of the yolk sac (white asterisk), yolk sac edema (dashed arrow), mild scoliosis. Developmental abnormalities were recorded using LAS EZ 3.2.0 digitizing software (https://www.leica-microsystems.com/ products/microscope-software/p/leica-las-ez/).

ture Activity Relationship (ECOSAR) v2.0 software (https:/www.epa.gov/tsca-screening-tools/ecological-struc ture-activity-relationships-ecosar-predictive-model) based on Quantitative Structure Activity Relationships (QSAR) models showed 4NC and CAT as the most toxic chemicals (Table 2). However, it is important to notice that experimental values for both compounds were approximately two times lower than the predicted ones. This led to the classification of $4 \mathrm{NC}$ into the group of molecules toxic to fish $\left(1<\mathrm{LC}_{50}<10 \mathrm{mg} / \mathrm{L}\right)$, and not only harmful as predicted by ECOSAR (Fig. 2). Furthermore, our study showed that GUA, although considered as harmful to fish, classifies as not harmful to zebrafish. As a result, estimated ECOSAR values could not be used for quantitative environmental risk assessment nor for prediction on compound's toxicity that could be applied for all fish species. In this study, ECOSAR-predicted values were provided for comparison to the obtained experimental values only. Differences between predicted and experimental values underline the increasing importance of accompanying in silico methods with in vivo toxicological tests, which is the only way to determine the compound's realistic toxic potential and evaluate its impact on the aquatic ecosystem. These issues are presented schematically in Fig. 2.

Differences in toxicity between CAT, GUA, and nitrated intermediates were already observed elsewhere ${ }^{24}$ and are highly dependent on the position of nitro groups on the benzene ring ${ }^{33}$. In their study, Pflieger and Kroflic ${ }^{24}$ observed an inhibitory effect on $V$. fischeri luminescence, which was 6-folds higher for bacteria exposed to $4,6 \mathrm{DNG}\left(\mathrm{EC}_{50}=16.7 \mathrm{mg} / \mathrm{L}\right)$ than the ones exposed to GUA $(100.6 \mathrm{mg} / \mathrm{L})$. A similar, although more pronounced toxicity trend was observed within this work, showing an eightfold higher toxicity of 4,6DNG compared to its non-nitrated form (Fig. 1a; Table 2). Such findings confirm the high sensitivity of zebrafish embryos to nitrated MPs and their toxicity potential due to their specific highly-reactive functional groups and chemical properties. Furthermore, as ECOSAR uses only the partitioning coefficient (log P) to predict fish toxicity it could underestimate MPs and nitro-MPs real toxic potential for chemicals acting through specific interactions and non-covalent binding to enzymes. This potential mode of action of MPs is also addressed in "In silico study: molecular modeling".

The most dominant abnormalities observed during the exposure to tested compounds were pericardial edema (Fig. 3e,h,j-l,n,o,s), blood accumulation in the yolk sac (Fig. 3n,p,s), and at later developmental stages (72, 96 hpf) skeletal deformities (Fig. 3f,h,i,r,s), undeveloped tail and necrosis of its apical part (Fig. 3g,h) and yolk sac edema (Fig. 3d,j,s). During the exposure to nitrated intermediates, blood accumulation in the brain region (Table S1, Fig. 3i) was also observed. Besides developmental abnormalities, the two most commonly observed endpoints were pigment formation failure (Fig. 3g,m) and non-hatching of larvae (Fig. 3e,h,n,o). Control group on artificial water developed normally (Fig. 3a-c). Based on Fig. 3 and Table S1 it can be concluded that the type of abnormality was not compound-related, but the sum of all obtained developmental abnormality types recorded on tested compounds $(4 \mathrm{NC}>\mathrm{CAT}=4,6 \mathrm{DNG}=5 \mathrm{NG}>\mathrm{GUA})$ mostly follows their toxic potential trend $(4 \mathrm{NC}>\mathrm{CAT}>4,6 \mathrm{DNG}>5 \mathrm{NG}>\mathrm{GUA})$.

The morphometric measurements (Fig. 4) showed that all tested samples significantly affected sensorial (eye area), skeletal (head height), and physiological (yolk and pericardial sac area) parameters in zebrafish. Significant differences among all treatments with exact $\mathrm{p}$ values are presented in Table S2.

The highest impact was noted on the size of the yolk sac area (Fig. 4c). A statistically significant increase of yolk sac area was observed among all tested samples, thus indicating a potential decline in metabolic rate and consequent decline in yolk consumption. The highest values of the yolk sac area were noted in larvae exposed to CAT $\left(169.1 \times 10^{3} \mu \mathrm{m}^{2}\right)$ and GUA $\left(170.3 \times 10^{3} \mu \mathrm{m}^{2}\right)$ compared to the control group $\left(85.9 \times 10^{3} \mu \mathrm{m}^{2}\right)$. It is important to emphasize that yolk consumption delay was not caused by growth retardation. One of the most frequently recorded sublethal endpoints during CAT and GUA exposure was pericardial edema (Table S1) which resulted in pericardial sac enlargement $\left(169.1\right.$ and $170.3 \times 10^{3} \mu \mathrm{m}^{2}$, respectively, compared to the control value of $85.9 \times 10^{3} \mu \mathrm{m}^{2}$ ) (Fig. 4d). CAT and GUA significantly impacted both measured physiological parameters, while skeletal structural parameters (Fig. 4a, b) were severely affected by GUA and nitrated intermediates. Compared to the control of untreated specimens, GUA caused the highest decrease in the zebrafish eye area $\left(13.1 \times 10^{3} \mu \mathrm{m}^{2}\right.$ compared to the control values of $\left.29.9 \times 10^{3} \mu \mathrm{m}^{2}\right)$ and head height $(244.8 \mu \mathrm{m}$ compared to the control values of $366.1 \mu \mathrm{m})$. The same decline in skeletal parameter values was noted during exposure to $4 \mathrm{NC}$ and $5 \mathrm{NG}$, and $4,6 \mathrm{DNG}$ (10.1-11.3\% decrease compared to the control values). This type of morphological measurement could serve as a valuable additional tool that has the potential to mitigate errors and limitations of qualitative analysis. 


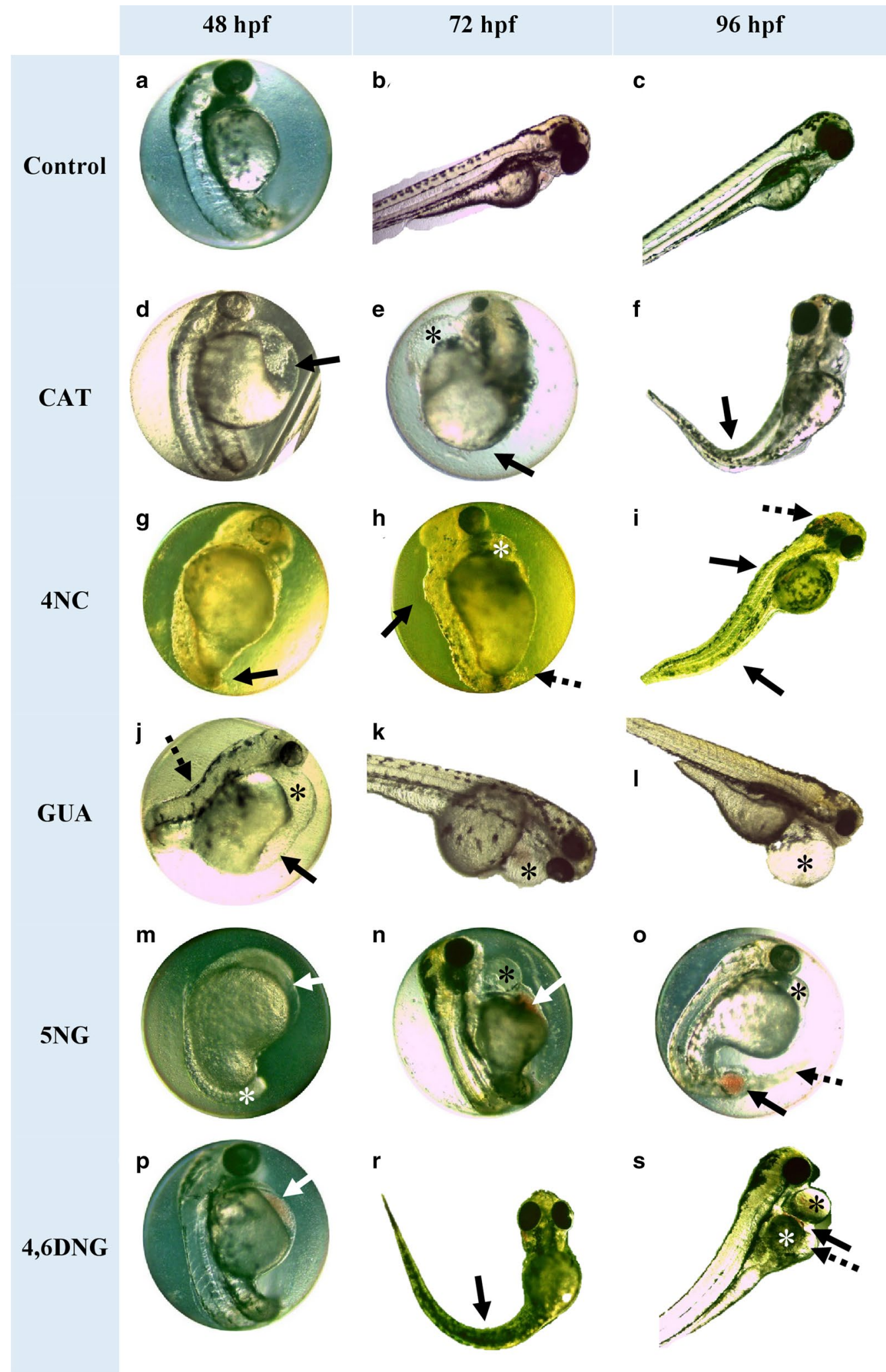


a

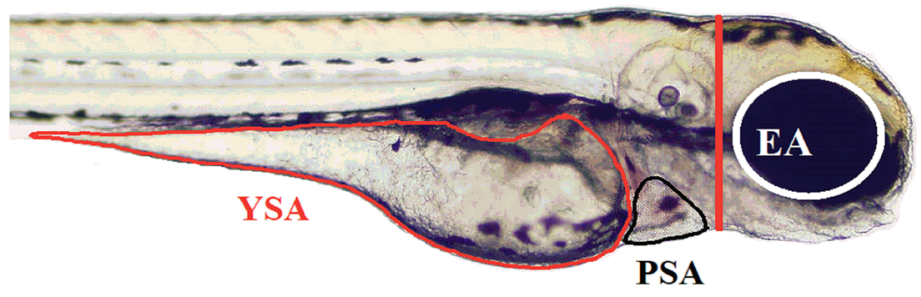

$1000 \mu \mathrm{m}$
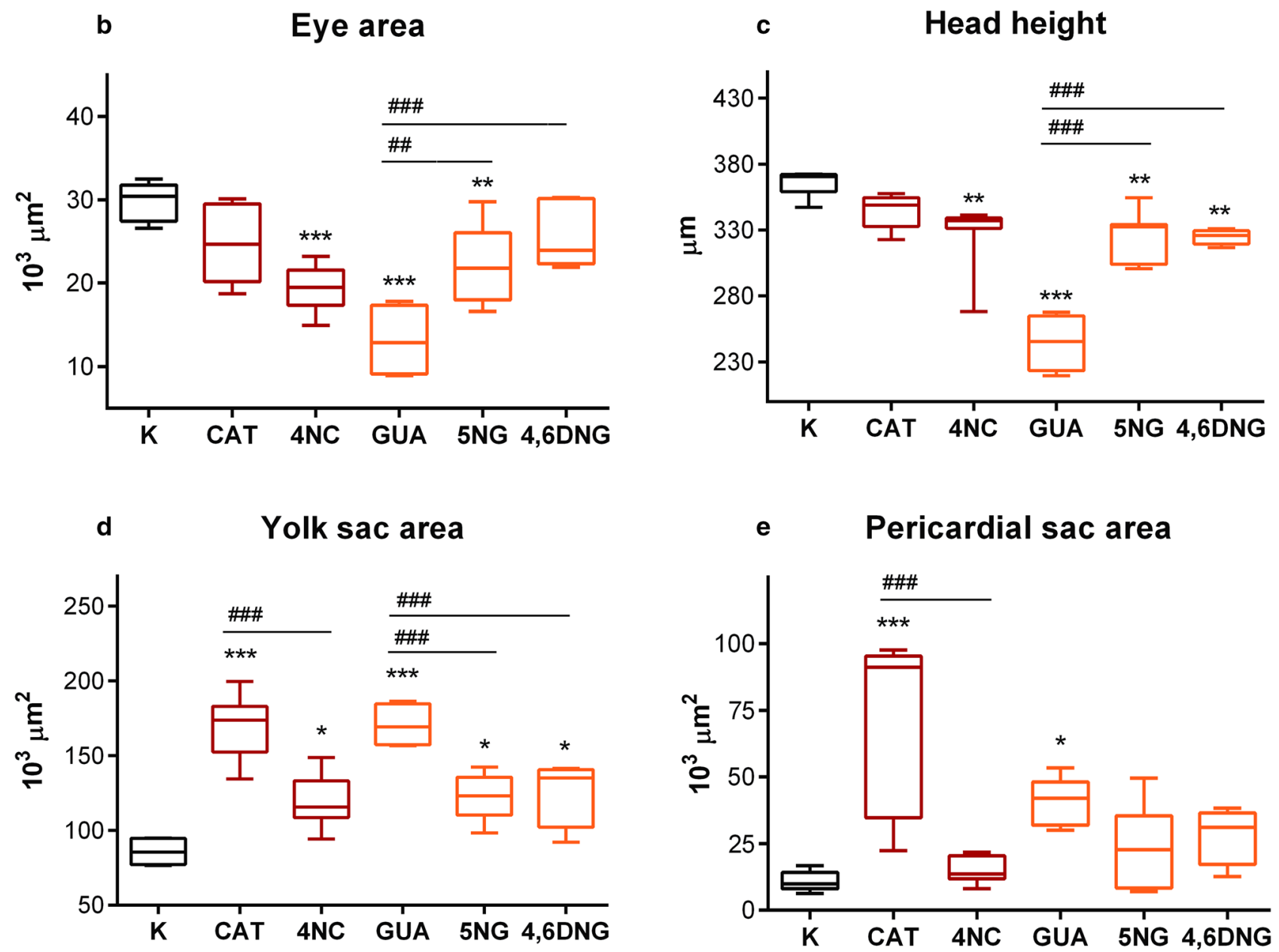

Figure 4. Morphometric measurements of D. rerio larvae after 96-h exposure to tested compounds (CAT, 4NC, GUA, 5NG, and 4,6DNG) and control (C). (a) Lateral view showing eye area (EA), head height (HH), yolk sac area (YSA), and pericardial sac area (PSA). Scale bar $=1000 \mu \mathrm{m}$. Morphometric parameters are presented by their mean value $(\mathbf{b}-\mathbf{e} ; \mathrm{n}=15)$. The symbol ${ }^{*}$ indicates a significant difference between tested samples and negative control $\left({ }^{*} \mathrm{p}<0.05 ;{ }^{* *} \mathrm{p}<0.01 ;{ }^{* *} \mathrm{p}<0.001\right)$. Mean values sharing common letters indicate significant differences among different tested compounds $\left({ }^{*} \mathrm{p}<0.05\right)$. A line within the box represents the median value, while the boundaries of box-plot indicate 25 th and 75 th percentiles. Whiskers above and below the box indicate 10th and 90th percentiles. Statistical analysis and data presentation were prepared using GraphPad Prism software version 6.0 (https://graphpad-prism.software.informer.com/6.0/), while visualization and morphometric measurements were performed using Microsoft AnalySIS Soft Imaging System software (https:// www.olympus-lifescience.com/en/support/downloads/).

In silico study: molecular modeling. A recent study has shown that GUA and CAT effectively inhibit different human CA isoenzymes with $K_{\mathrm{i}}$ in $\mathrm{mmol} / \mathrm{L}$ range $^{35}$. CA is a zinc-containing enzyme that catalyzes reversible interconversion between carbon dioxide and water into protons and bicarbonate ions. During zebrafish early development (24-48 hpf), embryos use CA for increased $\mathrm{CO}_{2}$ excretion $^{36}$. The activity of zebrafish CA5 isozyme 


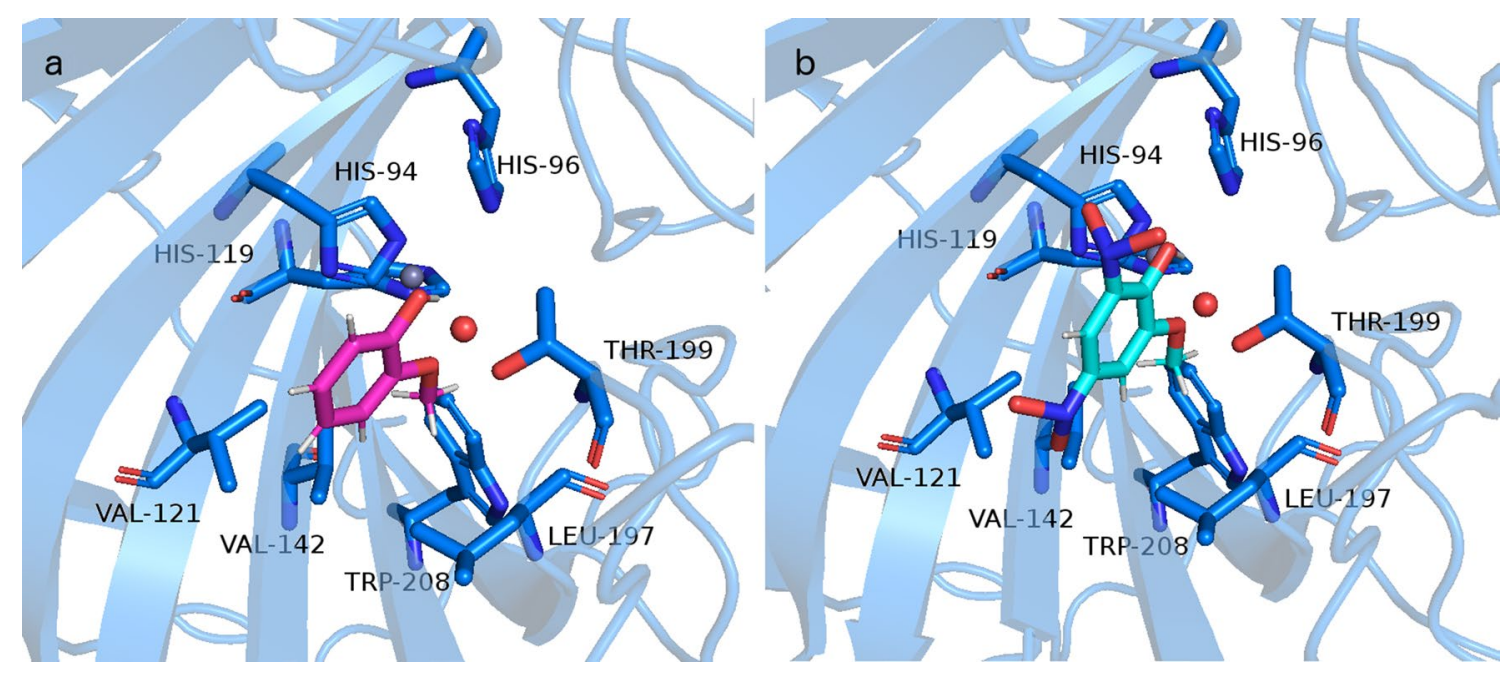

Figure 5. Representation of the interactions between (a) GUA and (b) 4,6DNG with the active site D. rerio CA II. Structure of D. rerio CA II (UniProt entry: Q92051) is modeled by I-TASSER, coordinates for Zn cation, and active site water molecule (oxygen atom in red) were taken from the structure of human CA deposited under PDB ID 1fql, whereas docking pose for GUA was obtained by SwissDock server. The same pose was obtained by AutoDock vina. Representation was made in PyMOL software (https://pymol.org/2/).

is shown to be essential for the regulation of acid-base balance during embryonic growth and its inhibition causes developmental abnormalities during embryonic development ${ }^{37}$. It was already shown that phenol and 2-nitrophenol are inhibitors of a cytosolic, human CA isoform II (hCA II) ${ }^{38,39}$. Namely, phenols bind to zincbound water through their $\mathrm{OH}$ moiety whereas the phenyl moiety is located in the hydrophobic part of the hCA II active site preventing binding of substrate $\mathrm{CO}_{2}$, thereby acting as inhibitors ${ }^{40}$.

Uniprot database possesses one manually annotated structure of zebrafish CA (CAH-Z), EC 4.2.1.1. (UniProt ID Q92051) that consists of 260 amino acids. Titration of this zebrafish CA isozyme with ethoxzolamide (EZA), a sulfonamide inhibitor, resulted in the subnanomolar $K_{\mathrm{i}}$ which was an indication that this zebrafish CA is a homolog to hCA II, which is also inhibited by sulfonamide inhibitors ${ }^{41}$. Alignment of zebrafish CA (CAH-Z) and hCA II, whose structure has been solved, resulted in $63 \%$ identities and $76 \%$ positives in primary sequences that account for highly homologous enzymes (Fig. S1). In addition to sulfonamide inhibitors, the previous study showed that catechols also inhibit hCA II isoform and because of high conservation in primary sequence between hCA II isoform and zebrafish CA isozyme we considered that catechol also inhibits zebrafish CA ${ }^{42}$. Therefore, we have modeled a 3D structure of zebrafish CA by using the I-TASSER server. With the obtained model we performed docking of the compounds tested in this study-CAT, GUA, 4NC, 5NG, and 4,6DNG. Docking proposed the same mode of binding as was previously explained for phenol, CAT, and GUA intermediates ${ }^{35,40}$. The corresponding predicted binding free energies of the docked structures (CAT, GUA, 4NC, 5NG, and 4,6DNG) obtained by AutoDock Vina are $-4.4,-4.5,-5.3,-5.5,-5.9 \mathrm{kcal} / \mathrm{mol}$ and by SwissDock are $-6.2,-6.1,-6.3$, $-6.2,-6.6 \mathrm{kcal} / \mathrm{mol}$, respectively. Lignin pyrolysis products and their nitrated intermediates bind within the $D$. rerio CA binding site in the same manner as was described for hCA II. Namely, in the case of GUA, interactions are made between GUA -OH moiety and water bound to the $\mathrm{Zn}$ cation. Methoxy moiety of GUA makes interactions with side-chain of Thr199, which is conserved amino acid among all CA, whereas methyl group from methoxy moiety and phenol part of the GUA make hydrophobic interactions with Leu197, Trp208, Val121, and Val142 (Fig. 5a). According to the docking results, all docked compounds have comparable binding free energies (within the standard error of the scoring function) to $4,6 \mathrm{DNG}$ showing slightly better affinities towards $D$. rerio CA. The obtained pose from 4,6DNG is virtually the same as described for GUA (Fig. $5 \mathrm{~b}$ ). It is known that nitro compounds $\left(-\mathrm{NO}_{2}\right)$ have a positive electrostatic potential named $\pi$-hole which can establish favorable interactions with lone-pair electrons ${ }^{43}$. Nitro group at the 6-position is directed towards the lone pairs of Ser56 -OH of the side chain, and side chains of Asn62 and Gln67 making favorable interactions.

In addition to inhibition of CA, recent studies have shown that our tested compounds can inhibit other enzymes shown to be essential for zebrafish embryo development ${ }^{44-47}$. Embryotoxicity results obtained within this study indicated that $4 \mathrm{NC}$, followed by CAT, GUA, 4,6DNG, and $5 \mathrm{NG}$ notably reduce or even prevent the formation of melanin (Table S1). Such a reduction/absence of pigmentation is usually caused by the ability of a compound to inhibit copper-containing enzyme tyrosinase, thus preventing the conversion of tyrosine into melanin ${ }^{48}$. CAT, GUA, and nitrated intermediates can serve as alternative substrates for tyrosinase, competing with tyrosine, which in turn results in reduced or even inhibited synthesis of melanin ${ }^{44-47}$. For instance, it has been already observed that tyrosinase from S. glaucescens is strongly inhibited by $4 \mathrm{NC}^{49}$. Therefore, the delay and absence of pigmentation observed within this study is most certainly the result of tyrosinase inhibition due to specific interactions with tested compounds (Table 2).

It has also been shown that $4 \mathrm{NC}$ strongly inhibits the iron-containing enzyme lipoxygenase that catalyzes the oxidation of unsaturated fatty acids to yield fatty acid hydroperoxides ${ }^{50}$. When the gene for lipoxygenase 
is subjected to the targeted knock-down, the zebrafish embryo displays an abnormal phenotype characterized by malformation of the brain, the eyes, and the tail as well as pericardial and yolk sac edema ${ }^{51}$. Therefore, compounds that inhibit lipoxygenase lead to the above-mentioned severe phenotype, which was also observed within this study.

GUA, CAT, and their nitrated derivatives $4 \mathrm{NC}, 4,6 \mathrm{DNG}$, and $5 \mathrm{NG}$ act jointly on different enzymes as targets (i.e. tyrosinase, lipoxygenase, and CA), leading to the abnormal phenotype that has been observed. Previous studies have shown that these enzymes are indeed important for the normal development of zebrafish specimens, whereas their inhibition or decreased expression leads to concurrent abnormalities that have been reported.

Our study has pinpointed $4 \mathrm{NC}$ and CAT as the most toxic compounds in the embryotoxicity test followed by 4,6DNG, 5NG, GUA, respectively. On the other hand, our docking study has revealed that all tested compounds in interaction with $D$. rerio CA II have binding free energies within the standard error of the scoring function making those compounds equally good inhibitors of this enzyme. Thus, tested compounds most likely act jointly on many different enzymes resulting in the abnormal phenotype that has been observed within our experiments.

\section{Conclusion}

Wood fires are the main part of an ongoing deforestation trend that reached the most concerning levels during an Amazonian biggest wildfire in 2019, as well as fires in Australia in 2019 and 2020. Amazonian wildfire in 2019 caused the deforestation of almost one million hectares and produced 140 million metric tons of carbon dioxide. Considering that softwood and hardwood burning release up to 0.36 and $0.19 \mathrm{mg}$ of guaiacol, 7.11 and $5.43 \mathrm{mg}$ of catechol, and 0.26 and $15.35 \mathrm{mg}$ of syringol, respectively, per $\mathrm{g}$ of emitted organic carbon, we can assume that several hundred tons of various MPs were released into the atmosphere in 2019 during these burning events. Such continuous input of MPs and their nitrated compounds into the aquatic environment could lead to currently unknown consequences if introduced in the food chain and river sediment.

Data reported in this study showed CAT and its nitrated intermediate (4NC) as the most toxic compounds, followed by 4,6DNG, 5NG, and GUA. The harmful effect of MPs on zebrafish embryonic development was manifested on multiple levels including cellular (i.e. inhibition of tyrosinase, lipoxygenase, and CA activity), morphological (i.e. head length and eye area reduction), physiological (i.e. delay in yolk consumption), and at the whole organism (i.e. occurrence of developmental abnormalities) levels. One of the first effects that occurred in zebrafish were developmental abnormalities and delayed hatching that consequently disturbed normal development and increased vulnerability to predation. Overall, observations recorded during MPs and nitro-MPs exposure demonstrated that zebrafish sensitivity can aid in early-pollution monitoring of these compounds in aquatic ecosystems.

Our data give an initial insight into the MPs toxicity potential to aquatic organisms (i.e. fish) and in particular to their early embryonal development. However, several limitations should be acknowledged. First, although the zebrafish embryotoxicity test and obtained results indicate significant progress and represent a reliable and inexpensive platform for further MPs testing, the system requires further expansion with other model aquatic organisms that might express different sensitivity levels. Furthermore, complex chemical processes and additional known/unknown product formation which occur during lignin thermal degradation and atmospheric reactions should be evaluated performing studies under real environmental conditions and taking into account potential synergistic actions. The limitation of QSAR predictive outputs could be overcome (but not completely) by integrating multiple computational models with different predictors, which is among all other mentioned issues a scope of our further studies.

Overall, only continuous research on atmospheric reactions, and identification of new intermediates in the environment, along with toxicological screening, will provide new data about fire-emitted products and their potential impact on our environment and health. Considering the increase of wildfire occurrences and their future trend under climate change, we believe that this study will serve as a base for all future investigations on MPs.

Received: 31 July 2020; Accepted: 11 January 2021

Published online: 28 January 2021

\section{References}

1. Carvalho, J. A. et al. $\mathrm{CO}_{2}$ and $\mathrm{CO}$ emission rates from three forest fire controlled experiments in Western Amazonia. Atmos. Environ. https://doi.org/10.1016/j.atmosenv.2016.03.043 (2016).

2. Yang, Y. et al. Post-drought decline of the Amazon carbon sink. Nat. Commun. https://doi.org/10.1038/s41467-018-05668-6 (2018).

3. Rödig, E. et al. From small-scale forest structure to Amazon-wide carbon estimates. Nat. Commun. https://doi.org/10.1038/s4146 7-019-13063-y (2019).

4. Chambers, J. Q. et al. The steady-state mosaic of disturbance and succession across an old-growth central Amazon forest landscape. Proc. Natl. Acad. Sci. USA https://doi.org/10.1073/pnas.1202894110 (2013).

5. Gatti, L. V. et al. Drought sensitivity of Amazonian carbon balance revealed by atmospheric measurements. Nature https://doi. org/10.1038/nature12957 (2014).

6. Aragão, L. E. O. C. et al. Interactions between rainfall, deforestation and fires during recent years in the Brazilian Amazonia. Philos. Trans. R. Soc. B https://doi.org/10.1098/rstb.2007.0026 (2008).

7. https://earthobservatory.nasa.gov/images/145649/mapping-the-amazon. Accessed on 23 Jul 2020.

8. http://queimadas.dgi.inpe.br/queimadas/portal-static/estatisticas_estados/. Accessed on 22 Nov 2020.

9. Ignotti, E. et al. Air pollution and hospital admissions for respiratory diseases in the subequatorial amazon: A time series approach. Cadernos Saude Publ. https://doi.org/10.1590/s0102-311x2010000400017 (2010).

10. Sigsgaard, T. et al. Health impacts of anthropogenic biomass burning in the developed world. Eur. Respir. J. https://doi. org/10.1183/13993003.01865-2014 (2015). 
11. https://climaesaude.icict.fiocruz.br/sites/climaesaude.icict.fiocruz.br/files/informe_observatorio_queimadas.pdf. Downloaded on 23 Jul 2020.

12. Wooster, M. J. et al. New tropical peatland gas and particulate emissions factors indicate 2015 Indonesian fires released far more particulate matter (but less methane) than current inventories imply. Remote Sens. https://doi.org/10.3390/rs10040495 (2018).

13. Wang, S., Ru, B., Lin, H., Sun, W. \& Luo, Z. Pyrolysis behaviors of four lignin polymers isolated from the same pine wood. Biores. Technol. https://doi.org/10.1016/j.biortech.2015.01.127 (2015).

14. Michałowicz, J., Stufka-Olczyk, J., Milczarek, A. \& Michniewicz, M. Analysis of annual fluctuations in the content of phenol, chlorophenols and their derivatives in chlorinated drinking waters. Environ. Sci. Pollut. Res. https://doi.org/10.1007/s11356-0110469-5 (2011).

15. Kroflič, A., Grilc, M. \& Grgić, I. Does toxicity of aromatic pollutants increase under remote atmospheric conditions?. Sci. Rep. https://doi.org/10.1038/srep08859 (2015).

16. Chen, X. et al. Mechanistic and kinetic investigations on the ozonolysis of biomass burning products: Guaiacol, syringol and creosol. Int. J. Mol. Sci. https://doi.org/10.3390/ijms20184492 (2019).

17. Deb, D. K. \& Sarkar, B. Formation of Criegee intermediates and peroxy acids: A computational study of gas-phase 1,3-cycloaddition of ozone with catechol. Phys. Chem. Chem. Phys. https://doi.org/10.1039/c9cp01312a (2019).

18. An, Z. et al. Theoretical study on the mechanisms, kinetics and ecotoxicity assessment of $\mathrm{OH}$-initiated reactions of guaiacol in atmosphere and wastewater. Sci. Total Environ. https://doi.org/10.1016/j.scitotenv.2019.06.229 (2019).

19. He, L., Schaefer, T., Otto, T., Kroflič, A. \& Herrmann, H. Kinetic and theoretical study of the atmospheric aqueous-phase reactions of OH radicals with methoxyphenolic compounds. J. Phys. Chem. A https://doi.org/10.1021/acs.jpca.9b05696 (2019).

20. Kitanovski, Z., Shahpoury, P., Samara, C., Voliotis, A. \& Lammel, G. Composition and mass size distribution of nitrated and oxygenated aromatic compounds in ambient particulate matter from southern and central Europe-implications for the origin. Atmos. Chem. Phys. https://doi.org/10.5194/acp-20-2471-2020 (2020).

21. Michałowicz, J. The natural and anthropogenic processes responsible for the presence of methoxyphenols in ecosystems and human surrounding. Annu. Set Environ. Protect. 10, 143-164 (2008).

22. Kitanovski, Z., Čusak, A., Grgić, I. \& Claeys, M. Chemical characterization of the main products formed through aqueous-phase photonitration of guaiacol. Atmos. Meas. Tech. https://doi.org/10.5194/amt-7-2457-2014 (2014).

23. Pöschl, U. \& Shiraiwa, M. Multiphase chemistry at the atmosphere-biosphere interface influencing climate and public health in the anthropocene. Chem. Rev. https://doi.org/10.1021/cr500487s (2015).

24. Pflieger, M. \& Kroflič, A. Acute toxicity of emerging atmospheric pollutants from wood lignin due to biomass burning. J. Hazard. Mater. https://doi.org/10.1016/j.jhazmat.2017.05.023 (2017).

25. ISO. Water quality: Determination of the acute lethal toxicity of substances to a freshwater fish (Brachydanio rerio HamiltonBuchanan (Teleostei, Cyprinidae)). Parts 1-3, (1996).

26. Council Directive 2010/63/EU. Council Directive 2010/63/EU on the protection of animals used for scientific purposes. Official Journal of the European Union. https://doi.org/10.3000/17252555.L_2010.276.eng (2010).

27. OECD. Test No. 236: Fish embryo acute toxicity (FET) test. OECD Guidelines for the Testing of Chemicals, Section 2, OECD Publishing. https://doi.org/10.1787/9789264203709-en (2013).

28. Yang, J. \& Zhang, Y. I-TASSER server: New development for protein structure and function predictions. Nucleic Acids Res. https ://doi.org/10.1093/nar/gkv342 (2015).

29. Sterling, T. \& Irwin, J. J. ZINC 15: Ligand discovery for everyone. J. Chem. Inf. Model. https://doi.org/10.1021/acs.jcim.5b00559 (2015).

30. Grosdidier, A., Zoete, V. \& Michielin, O. SwissDock, a protein-small molecule docking web service based on EADock DSS. Nucleic Acids Res. https://doi.org/10.1093/nar/gkr366 (2011).

31. Kawabata, T. Detection of cave pockets in large molecules: Spaces into which internal probes can enter, but external probes from outside cannot. Biophys. Physicobiol. 16, 1-2 (2019).

32. Pettersen, E. F. et al. UCSF Chimera: A visualization system for exploratory research and analysis. J. Comput. Chem. https://doi. org/10.1002/jcc.20084 (2004).

33. Nałęcz-Jawecki, G. \& Sawicki, J. Influence of $\mathrm{pH}$ on the toxicity of nitrophenols to Microtox and Spirotox tests. Chemosphere https ://doi.org/10.1016/S0045-6535(02)00865-2 (2003).

34. Council Directive 67/548/EEC. ANNEX VI General classification and labelling requirements for dangerous substances and preparations. J. Eur. Union (1967).

35. Scozzafava, A., Passaponti, M., Supuran, C. T. \& Gülçin, I. Carbonic anhydrase inhibitors: Guaiacol and catechol derivatives effectively inhibit certain human carbonic anhydrase isoenzymes (hCA I, II, IX and XII). J. Enzyme Inhib. Med. Chem. https://doi. org/10.3109/14756366.2014.956310 (2015).

36. Gilmour, K. M., Thomas, K., Esbaugh, A. J. \& Perry, S. F. Carbonic anhydrase expression and CO2 excretion during early development in zebrafish Danio rerio. J. Exp. Biol. https://doi.org/10.1242/jeb.034116 (2009).

37. Postel, R. \& Sonnenberg, A. Carbonic anhydrase 5 regulates acid-base homeostasis in zebrafish. PLoS ONE https://doi.org/10.1371/ journal.pone.0039881 (2012)

38. Simonsson, I., Jonsson, B. H. \& Lindskog, S. Phenol, a competitive inhibitor of $\mathrm{CO}_{2}$ hydration catalyzed by carbonic anhydrase. Biochem. Biophys. Res. Commun. https://doi.org/10.1016/S0006-291X(82)80063-6 (1982).

39. Tibell, L., Forsman, C., Simonsson, I. \& Lindskog, S. The inhibition of human carbonic anhydrase II by some organic compounds. Biochem. Biophys. Res. Commun. 829, 202-208 (1985).

40. Nair, S. K., Ludwig, P. A. \& Christianson, D. W. Two-site binding of phenol in the active site of human carbonic anhydrase II: Structural implications for substrate association. J. Am. Chem. Soc. https://doi.org/10.1021/ja00087a086 (1994).

41. Peterson, R. E., Tu, C. \& Linser, P. J. Isolation and characterization of a carbonic anhydrase homologue from the zebrafish (Danio rerio). J. Mol. Evol. https://doi.org/10.1007/PL00006163 (1997).

42. Innocenti, A., Hilvo, M., Scozzafava, A., Parkkila, S. \& Supuran, C. T. Carbonic anhydrase inhibitors: Inhibition of the new membrane-associated isoform XV with phenols. Bioorg. Med. Chem. Lett. https://doi.org/10.1016/j.bmcl.2008.04.077 (2008).

43. Bauzá, A., Frontera, A. \& Mooibroek, T. J. $\pi$-hole interactions involving nitro aromatic ligands in protein structures. Chem. Eur. J. 25, 13436 (2019).

44. Ramsden, C. A. \& Riley, P. A. Tyrosinase: The four oxidation states of the active site and their relevance to enzymatic activation, oxidation and inactivation. Bioorg. Med. Chem. https://doi.org/10.1016/j.bmc.2014.02.048 (2014).

45. Panzella, L. \& Napolitano, A. Natural and bioinspired phenolic compounds as tyrosinase inhibitors for the treatment of skin hyperpigmentation: Recent advances. Cosmetics https://doi.org/10.3390/cosmetics6040057 (2019).

46. Garcia-Molina, M. D. M., Muñoz-Muñoz, J. L., Garcia-Molina, F., García-Ruiz, P. A. \& Garcia-Canovas, F. Action of tyrosinase on ortho-substituted phenols: Possible influence on browning and melanogenesis. J. Agric. Food Chem. https://doi.org/10.1021/jf301 238q (2012).

47. Duckworth, H. W. \& Coleman, J. E. Physicochemical and kinetic properties of mushroom tyrosinase. J. Biol. Chem. https://doi. org/10.1016/S0031-9422(00)82247-5 (1970).

48. Carlsson, G., Norrgren, L., Hylland, K. \& Tollefsen, K. Toxicity screening of produced water extracts in a zebrafish embryo assay. J. Toxicol. Environ. Health A 77, 600-615 (2014). 
49. Lerch, K. \& Ettlinger, L. Purification and characterization of a tyrosinase from Streptomyces glaucescens. Eur. J. Biochem. https:// doi.org/10.1111/j.1432-1033.1972.tb02549.x (1972).

50. Skrzypczak-Jankun, E., Borbulevych, O. Y. \& Jankun, J. Soybean lipoxygenase-3 in complex with 4-nitrocatechol. Acta Crystallogr. D https://doi.org/10.1107/S0907444904000861 (2004).

51. Haas, U. et al. Targeted knock-down of a structurally atypical zebrafish $12 \mathrm{~S}$-lipoxygenase leads to severe impairment of embryonic development. Proc. Natl. Acad. Sci. USA https://doi.org/10.1073/pnas.1117094108 (2011).

\section{Acknowledgements}

This study was partially supported by the Scientific Centre of Excellence for Marine Bioprospecting-BioProCro, a project co-financed by the Croatian Government and the European Union through the European Regional Development Fund-the Competitiveness and Cohesion Operational Programme (KK.01.1.1.01). GUA, CAT, as well as their nitrated forms 4,6DNG, $5 \mathrm{NG}$, and $4 \mathrm{NC}$ were generously provided by the Department of Analytical Chemistry of the National Institute of Chemistry, Ljubljana.

\section{Author contributions}

S.B., M.P., and P.T. formulated the concept of this research and set up research design. S.B. and L.Č. performed the experiment and analyzed the data. A.M. conducted computational calculations. O.M. and P.T. supervised the work. S.B., L.Č., O.M. wrote the manuscript with help from I.S.P. and N.T.P., and constructive feedback and editing from M.P., R.Č.R., P.T. All authors discussed, reviewed, and approved the contents within the manuscript.

\section{Competing interests}

The authors declare no competing interests.

\section{Additional information}

Supplementary Information The online version contains supplementary material available at https://doi. org/10.1038/s41598-021-81789-1.

Correspondence and requests for materials should be addressed to O.M. or P.T.

Reprints and permissions information is available at www.nature.com/reprints.

Publisher's note Springer Nature remains neutral with regard to jurisdictional claims in published maps and institutional affiliations.

(c) (i) Open Access This article is licensed under a Creative Commons Attribution 4.0 International License, which permits use, sharing, adaptation, distribution and reproduction in any medium or format, as long as you give appropriate credit to the original author(s) and the source, provide a link to the Creative Commons licence, and indicate if changes were made. The images or other third party material in this article are included in the article's Creative Commons licence, unless indicated otherwise in a credit line to the material. If material is not included in the article's Creative Commons licence and your intended use is not permitted by statutory regulation or exceeds the permitted use, you will need to obtain permission directly from the copyright holder. To view a copy of this licence, visit http://creativecommons.org/licenses/by/4.0/.

(C) The Author(s) 2021 